\section{Retrieval of a sharp foreign body from the stomach: a novel approach}

An 82-year-old man presented to the emergency room following an episode of dark tarry stools. Esophagogastroduodenoscopy (EGD) revealed an 8-mm nonbleeding, cratered ulcer in the gastric antrum. A piece of glass was noted to be embedded in the antral wall within the ulcer base ( $\bullet$ Fig. 1 a).

An attempt was made to retrieve the embedded glass using small forceps, but this resulted in a small piece being chipped away, although this was then safely with- drawn ( Fig. 1 b). Elective airway intubation was therefore performed to allow further procedures to be carried out. In order to avoid mucosal trauma while the sharp piece of glass was being removed, especially perforation at the gastroesophageal junction, an enteroscope with a singleballoon overtube was inserted. A Roth Net was used to retrieve the object after it had been freed from the antral wall $(\bullet$ Fig. 1 c). However, the Roth Net was torn by the piece of glass ( $\bullet$ Fig. $1 \mathrm{~d}$ ), which then became stuck to the distal
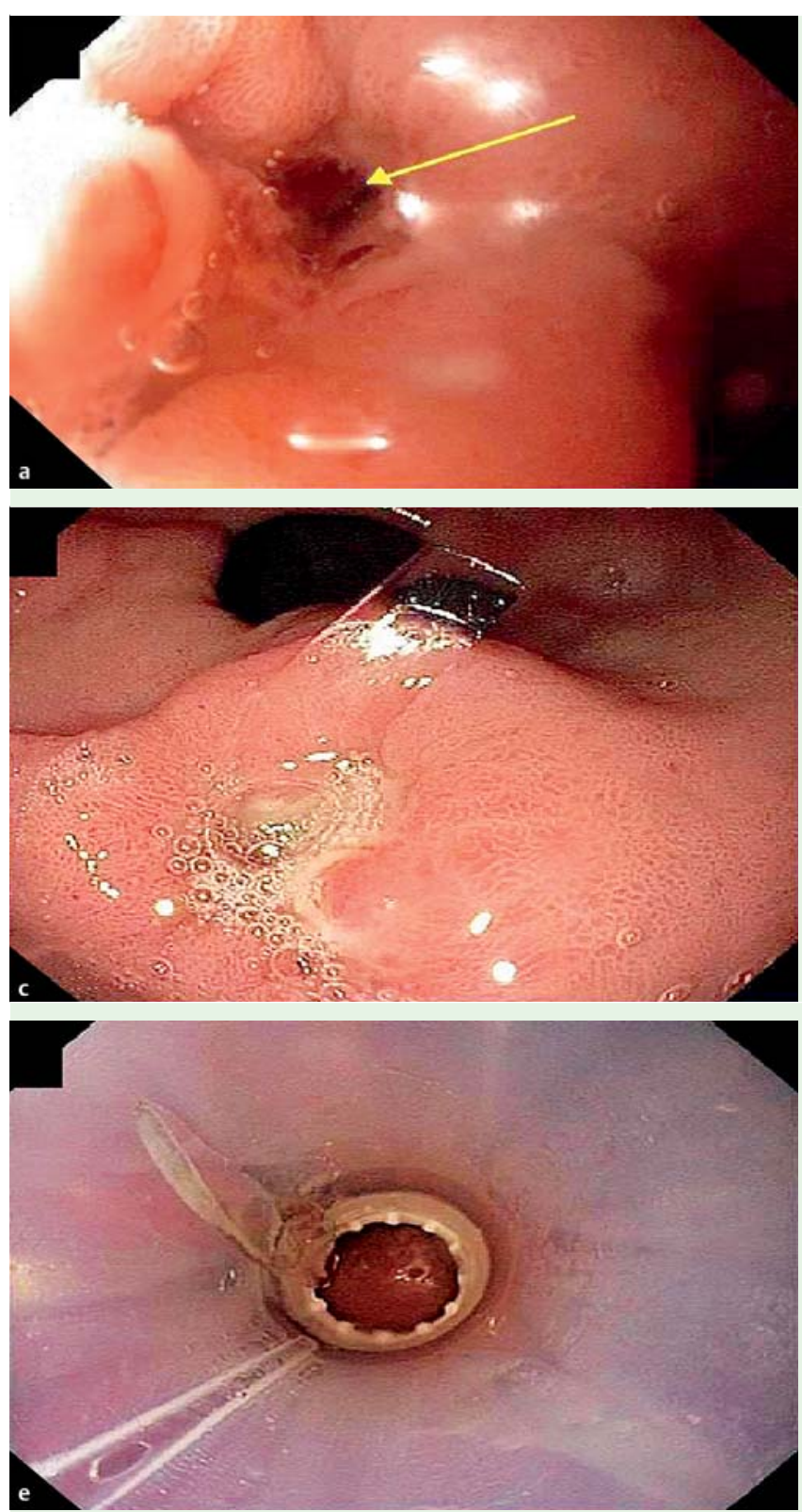

Fig. 1 Esophagogastroduodenoscopy (EGD) in an 82-year-old man who presented with dark tarry stools. a An 8-mm nonbleeding, cratered ulcer in the gastric antrum with glass embedded in the antral wall (arrow). b A small piece of glass that was chipped off during attempted retrieval with small forceps. c The piece of glass, which was freed from the antral wall using a Roth Net. d The glass clinging to the wall of the overtube, after its retrieval was complicated when the Roth Net was torn during attempted withdrawal.
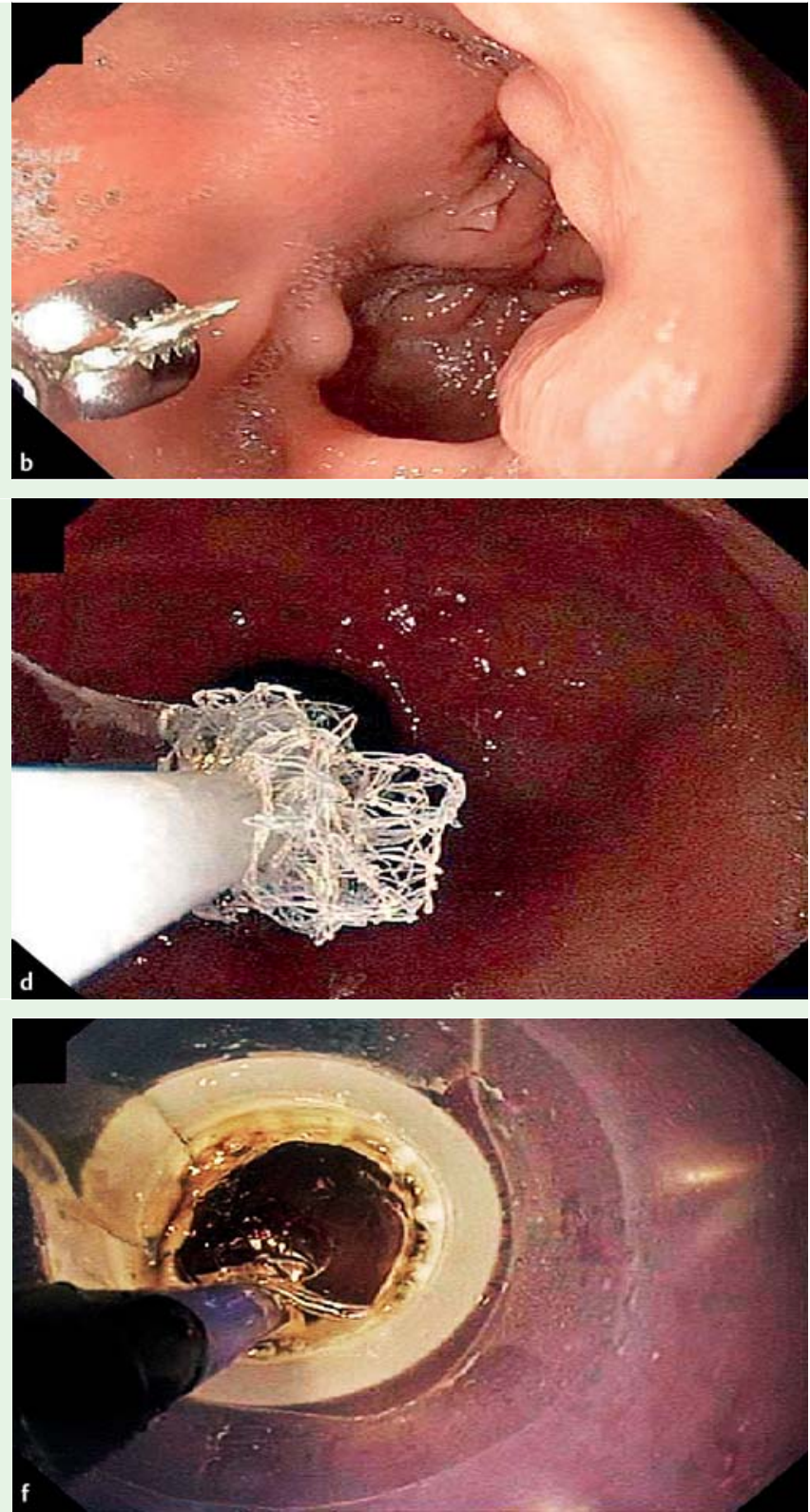

e The piece of glass located at the distal end of the overtube (10 o'clock position), from where it could easily have been displaced distally into stomach. $\mathbf{f}$ The piece of glass within the overtube during its retrieval using a dilation balloon, which was inflated in the stomach distal to foreign body then drawn proximally through the overtube to safely remove the glass. 
end of the overtube ( $\bullet$ Fig.1e), from where it could easily have been displaced distally into the stomach.

To prevent the piece of glass falling back into the stomach, a dilation balloon was passed through the overtube and was inflated in the stomach distal to the foreign body ( Fig. 1f). The glass was then safely withdrawn under direct visualization by pulling the dilation balloon proximally through the overtube. After removal of the glass, the enteroscope was reintroduced, and further examination revealed no signs of active bleeding, clot, or trauma to the esophagus or oropharynx. The initial area of ulceration was clipped to correct the mucosal defect.

Foreign body ingestion is relatively common and usually results in spontaneous passage [1]. In cases involving sharp objects, early endoscopic retrieval should be initiated [1]. Complications following the ingestion of a sharp foreign body include esophageal perforation [2] and gastric perforation [3]. Endoscopic overtubes have been shown to be beneficial for esophageal protection when retrieving a foreign body $[4,5]$. In this case, the edges of the foreign body caught the overtube. The decision was therefore made to use a dilation balloon deployed distal to the object, which was then withdrawn through the overtube under direct visualization, this being a novel approach to the retrieval of a difficult gastric foreign body.
Endoscopy_UCTN_Code_TTT_1AO_2AL

Competing interests: None

\section{Adam Bledsoe ${ }^{1}$, Brett Baloun ${ }^{1,2}$, Jeffrey Murray $^{1,2}$, Muslim Atiq ${ }^{1,2}$}

${ }^{1}$ University of South Dakota - Sanford School of Medicine, Sioux Falls,

South Dakota, USA

2 Sanford Center for Digestive Health, Sanford USD Medical Center, Sioux Falls, South Dakota, USA

\section{References}

1 Smith MT, Wong RKH. Esophageal foreign bodies: Types and techniques for removal. Curr Treat Options Gastroenterol 2006; 9: $75-84$

2 Vilallonga $R$, Pimentel $R$, Rosenthal $R$. A hybrid endolaparoscopic therapy for the treatment of foreign bodies in the stomach with esophageal perforation. Surg Laparosc Endosc Percutan Tech 2013; 23: 337-340

3 Mehran A, Podkameni $D$, Rosenthal $R$ et al. Gastric perforation secondary to ingestion of a sharp foreign body. J Soc Laparoendosc Surg 2005; 9: 91 -93

4 Seo YS, Park JJ, Kim JH et al. Removal of press-through-packs impacted in the upper esophagus using an overtube. World J Gastroenterol 2006; 12: 5909-5912

5 Alhaji M, Atreja A, Upchurch BR. Razor blade removal from the stomach utilizing a novel modification of the overtube. Endoscopy 2009; 41: E166
Bibliography

Dol http://dx.doi.org/

10.1055/s-0033-1359189

Endoscopy 2014; 46: E105-E106

(c) Georg Thieme Verlag KG

Stuttgart · New York

ISSN 0013-726X

Corresponding author

Adam Bledsoe

University of South Dakota

Sanford School of Medicine

1400 West 22nd Street

Sioux Falls

SD 57105

USA

Fax: +1-605-357-1311

Adam.Bledsoe@usd.edu 